\title{
Theoretical study on the atmospheric transformation mechanism of pirimiphos-methyl initiated by $\mathrm{O}_{3}$
}

\author{
Bo Yang ${ }^{\mathrm{a}, *}$, Youfeng Wang ${ }^{\mathrm{a}}$, Jinian Shu ${ }^{\mathrm{a}}$, Peng Zhang ${ }^{\mathrm{a}}$, Wanqi Sun ${ }^{\mathrm{a}}$, Nana Li $^{\mathrm{a}}$, Yani Zhang ${ }^{\mathrm{b}}$ \\ ${ }^{a}$ Research Center for Eco-Environmental Sciences, Chinese Academy of Sciences, Beijing 100085, China \\ ${ }^{\mathrm{b}}$ Beijing City Environmental Protection Bureau of Xicheng District, Beijing 100032, China
}

\section{H I G H L I G H T S}

- The reaction mechanism of pirimiphos-methyl with $\mathrm{O}_{3}$ is proposed.

- Four kinds of degradation products are obtained.

- Water can serve as a catalyst in the $N$-dealkylation reaction process.

- The subsequent reactions tend to occur spontaneously once the reaction initiates.

\section{A R T I C L E I N F O}

\section{Article history:}

Received 6 August 2014

Received in revised form 1 December 2014

Accepted 8 December 2014

Available online 3 January 2015

Handling Editor: Klaus Kümmerer

\section{Keywords:}

Pirimiphos-methyl

Reaction mechanism

$\mathrm{O}_{3}$

Pesticides

DFT

Atmospheric transformation

\begin{abstract}
A B S T R A C T
Pirimiphos-methyl (PMM) is a widely used organophosphorus pesticide that can be released into the atmosphere in gas and condensed phases. It possesses a $\mathrm{P}=\mathrm{S}$ bond and an $N, N$-dialkyl group adjacent to pyrimidine, which are common functional groups for pesticides. Currently, the reaction mechanisms of $\mathrm{O}_{3}$ with these functional groups are poorly understood. In this study, the mechanisms and possible degradation products for $\mathrm{O}_{3}$-initiated atmospheric oxidation of PMM were investigated using the Density Functional Theory (DFT) method. The results show that $\mathrm{H}$ abstraction from the alpha carbon of the $N, N$-diethyl group and its subsequent reactions (hydroxylation, $N$-dealkylation, and carbonylation reactions), as well as the transformation of the $\mathrm{P}=\mathrm{S}$ bond to the $\mathrm{P}=\mathrm{O}$ oxone form, are the most favorable reaction pathways for PMM and $\mathrm{O}_{3}$. The Gibbs free energy $(\Delta G)$ indicates that the subsequent reactions tend to take place more spontaneously once the initial reaction occurs. In addition, theoretical calculations indicate that water can serve as an effective catalyst in the $\mathrm{N}$-dealkylation reaction process. Water-assisted reactions lead to the activation energy decreasing by $20.2 \mathrm{kcal} \mathrm{mol}^{-1}$ compared with direct reactions, and thus may represent a dominant reaction pathway for the $N$-dealkylation process in the atmosphere. These theoretical results provide new insights into $\mathrm{O}_{3}$-initiated degradation of PMM and its analogues.
\end{abstract}

(c) 2014 Elsevier Ltd. All rights reserved.

\section{Introduction}

Pirimiphos-methyl (PMM, shown in Fig. 1) is a broad-spectrum organophosphorus pesticide, which acts as an insecticide and fumigant for controlling a wide range of insects (Fleurat-Lessard et al., 2007). Since its original development in 1967, PMM has been extensively used on domestic and industrial premises. Recently, owing to vector resistance to both pyrethroids and DDT, causing an increasing threat to effective "malaria vector control" across Africa, PMM was approved as an alternative insecticide by the World Health Organization's Pesticide Evaluation Scheme (WHOPES) for its high toxicity to anopheline mosquitoes

\footnotetext{
* Corresponding author. Tel.: +86 0106284 9087; fax: +86 01062923563 .

E-mail address: boyang@rcees.ac.cn (B. Yang).
}

(Tangena et al., 2013; Ngufor et al., 2014; Oxborough et al., 2014). The widespread use of PMM inevitably gives rise to pollution in eco-environments. It has a toxic effect on non-target living organisms such as fish, birds, and mammals, including humans (Seiler, 1973; Hanna and Dyer, 1975; Moriya et al., 1983; Rajini et al., 1986; Lock and Johnson, 1990; Hladka et al., 1991; Crane et al., 1999). Occupational workers exposed to PMM may experience DNA damage, a decrease in acetyl cholinesterase (AChE) activity, and hepatotoxicity as well as nephrotoxicity (Singh et al., 2011).

PMM can be released into the atmosphere directly during spraying; a vapor pressure of $2.0 \times 10^{-3} \mathrm{~Pa}$ at $20^{\circ} \mathrm{C}$ allows PMM to exist in both the gas and particulate phases in the atmosphere. It is removed from the atmosphere by wet or dry deposition, or degraded by reactions with atmospheric oxidants. Understanding 
the atmospheric degradation of PMM is crucial in assessing its behavior and potential risk to non-targets. However, current knowledge concerning this topic is very limited. The UV-VIS spectrum of PMM (shown in Fig. S2 of Supporting Information) has an overlap with the sunlight spectrum, suggesting a potential direct photolysis of PMM by sunlight. However, the photolysis rate of gas-phase PMM is unavailable. Previous studies showed that the life-times of PMM in green cowpea pods and on films through photolysis by direct sunlight were $5 \mathrm{~d}$ (Barakat et al., 1994) and that in aqueous containing $\mathrm{TiO}_{2}$ catalyst was $0.7 \mathrm{~h}$ (Herrmann et al., 1999). The atmospheric life-time of PMM through direct photolysis may be at the similar order of magnitude to the previous investigations. Moreover, PMM is supposed to be degraded in the atmosphere by reaction with $\mathrm{OH}$ radicals, and the half-life for this reaction is estimated to be $2.4 \mathrm{~h}$ using a structure estimation method (Meylan and Howard, 1993). Previous studies of PMM's degradation pathways focused primarily its behavior in water, including the degradation of PMM in industrial water under $\mathrm{O}_{3}$ treatment (Chiron et al., 1998) and the photocatalytic degradation of PMM in solution (Herrmann et al., 1999). Besides hydrolysis of the phosphoric ester function, $\mathrm{N}$-dealkylation of $\mathrm{N}, \mathrm{N}$-diethyl groups and carbonylation of alkyl groups are two primary reaction pathways for PMM where the reaction mechanism is unclear. In our earlier studies, gaseous $\mathrm{O}_{3}$ was found to have a high reactivity with particulate PMM (rate constant $=(1.97 \pm 0.25) \times 10^{-17} \mathrm{~cm}^{3}$ molecules ${ }^{-1} \mathrm{~s}^{-1}$ at $298 \mathrm{~K}$ ), corresponding to an atmospheric half-time of $8.9 \mathrm{~h}$ at 40 ppbv of $\mathrm{O}_{3}$ (Yang et al., 2010). This reaction also results in the formation of $\mathrm{N}$-dealkylation and carbonylation products. Thus, considering that sunlight and $\mathrm{OH}$ radicals are only abundant in the day time while $\mathrm{O}_{3}$ exists both in the day and night time, the reaction with $\mathrm{O}_{3}$ is a potential important degradation pathway for PMM in the atmosphere.

$\mathrm{O}_{3}$ is one of the most common oxidants in the atmosphere with a relatively high concentration compared to $\mathrm{NO}_{3}$ and $\mathrm{OH}$ radicals (Vingarzan, 2004). In past research, $\mathrm{O}_{3}$ was only considered an important reactant for unsaturated $\mathrm{C}=\mathrm{C}$ bonds (FinlaysonPitts and Pitts, 1997), and its reactions with other functional groups were almost entirely ignored. The reaction mechanisms involved were not well known, such as the above-mentioned $\mathrm{O}_{3}$-induced $\mathrm{N}$-dealkylation and carbonylation reactions, as well as the transformation of $\mathrm{P}=\mathrm{S}$ to $\mathrm{P}=\mathrm{O}$, reported widely in the ozonation of organophosphorus pesticides (Ohashi et al., 1994; Herrmann et al., 1999). $\mathrm{PMM}$ is a compound that has both a typical $\mathrm{P}=\mathrm{S}$ bond for organo-

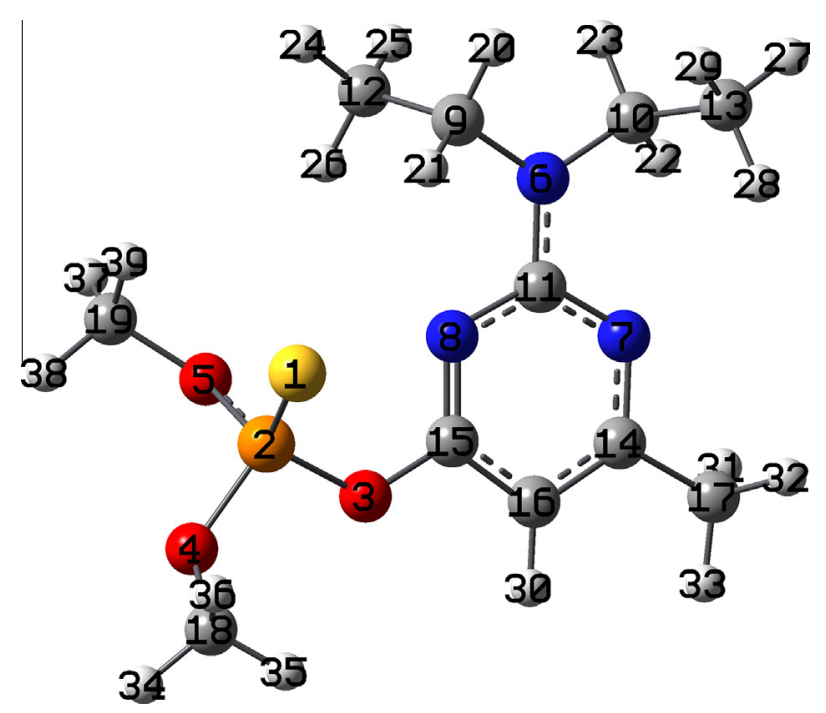

Fig. 1. The labeled number in the structure of PMM. phosphorus pesticides and a $N, N$-dialkyl substituted pyrimidine structure, which possesses high biological activity and has been synthesized for various purposes, including insect repellents, industrial solvents, and respiratory stimulants (Ross et al., 1983; Robbins and Cherniack, 1986; Gescher, 1990). Therefore, in this paper, a theoretical study of the $\mathrm{O}_{3}$-induced atmospheric reaction of PMM was performed. The proposed reaction mechanisms and degradation products may provide helpful information on the atmospheric degradation of PMM and its analogue substances.

\section{Computational method}

All calculations were performed using the Gaussian 09 program and employed the unrestricted hybrid density functional method B3LYP (Frisch et al., 2009). Geometrical parameters of the reactants, intermediates, transition states, and products were fully optimized using the standard basis set $6-31 G(d, p)$. The nature of stationary points, the zero-point energy (ZPE), and the thermal contribution to the free energy of activation were determined by the vibrational frequency calculation at the same level. For each transition state, the intrinsic reaction coordinate (IRC) calculation was performed using the same level of electronic structure theory to verify that the transition state connected the correct intermediate structures. To evaluate the energetic parameters more accurately, a more flexible basis set, $6-311++G(3 d f, 2 p)$, was employed to calculate the single-point energy of various species. Moreover, because of the deficiencies of Density Functional Theory (DFT) in calculating singlet oxygen, we calculated the corresponding triplet oxygen energies and corrected the results with the experimental tripletsinglet splitting enthalpy of $22.64 \mathrm{kcal} \mathrm{mol}^{-1}$ (Tuttle et al., 2004).

\section{Results and discussion}

\section{1. $\mathrm{H}$ abstraction by $\mathrm{O}_{3}$ and subsequent reactions}

Studies have shown that ozonation of the $\mathrm{CH}$ bond in saturated hydrocarbons initiates with $\mathrm{H}$ abstraction by $\mathrm{O}_{3}$, followed by the formation of an $\mathrm{R} \cdot \mathrm{OOOH}$ radical pair (Cerkovnik et al., 2002; Yang et al., 2008; Voukides et al., 2009). Within the structure of PMM, seven different kinds of hydrogen can be abstracted by $\mathrm{O}_{3}$, as shown in Fig. 2. These reaction channels have different potential barriers $(\Delta E)$ and reaction heats $(\Delta H)$. It should be noted that $\mathrm{H}$ abstractions only occur on alkyl groups. The transition state describing the $\mathrm{H}_{30}$ abstraction of the $\mathrm{H}$-atom adjacent to pyrimidine ring was not identified successfully, which may be due to the resonance of the pyrimidine ring with the $\mathrm{H}_{30}$ atom. Hence, we speculate that this kind of $\mathrm{H}$-atom in PMM cannot be abstracted by $\mathrm{O}_{3}$ at $1.0 \mathrm{~atm}$. pressure and $298 \mathrm{~K}$. In this paper, the abstraction of $\mathrm{H}_{20}$ is taken as an example to elucidate the detailed $\mathrm{H}$ abstraction process and subsequent reactions. Figs. 3 and 4 show the proposed reaction mechanisms for PMM with $\mathrm{O}_{3}$, and the corresponding potential energy surface for each reaction pathway. Table 1 exhibits the involved relative energies $(\Delta E)$, relative enthalpies $(\Delta H)$, and Gibbs free energies $(\Delta G)$ calculated using the $6-31 \mathrm{G}(\mathrm{d}, \mathrm{p})$ basis set, and also the $\Delta E$ calculated using the $6-311++\mathrm{G}(3 \mathrm{df}, 2 \mathrm{p})$ basis set. The subsequent reactions following other $\mathrm{H}$ abstraction channels (abstraction of $\mathrm{H}_{22}, \mathrm{H}_{24}, \mathrm{H}_{27}$, $\mathrm{H}_{33}, \mathrm{H}_{34}$, and $\mathrm{H}_{38}$ ) were also calculated. The relevant information on $\Delta E, \Delta H$, and $\Delta G$ is shown in Fig. $\mathrm{S} 1$ (Supporting Information).

In the $\mathrm{H}_{20}$ abstraction process, the $\mathrm{H}$-atom is abstracted by $\mathrm{O}_{3}$ via a transition state (TS1), and generates the intermediate IM1 and an $\mathrm{OOOH}$ radical. The potential barrier is $9.4 \mathrm{kcal} \mathrm{mol}^{-1}$ and the reaction is slightly endothermic, $1.5 \mathrm{kcal} \mathrm{mol}^{-1}$ of energy. In TS1, the bond length of $\mathrm{C}_{9} \mathrm{H}_{20}$ is $1.413 \AA$, which is $0.318 \AA$ longer than that of $\mathrm{C}_{9} \mathrm{H}_{20}$ in PMM, and the $\mathrm{H}_{20}$ atom shows an apparent 


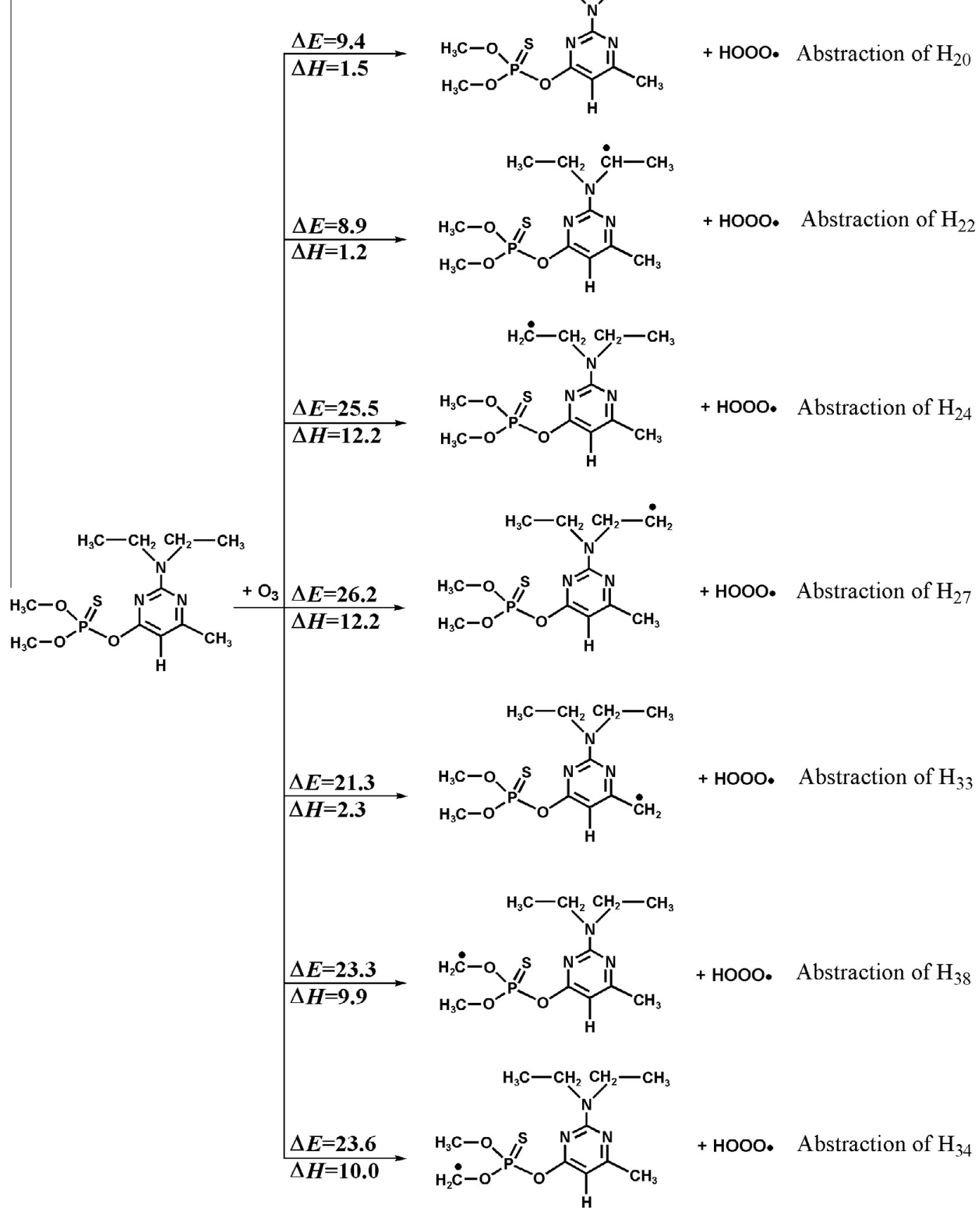

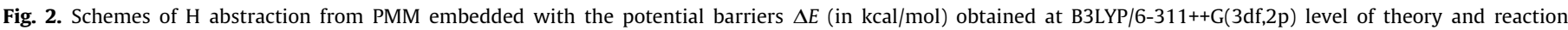
enthalpies $\Delta H$ (in $\mathrm{kcal} / \mathrm{mol}, 0 \mathrm{~K}$ ) obtained at B3LYP/6-31G(d,p) level of theory.

transformation to the $\mathrm{O}_{3}$ molecule. Abstractions of other $\mathrm{H}$ atoms are similar to the abstraction of $\mathrm{H}_{20}$. Comparing these seven channels, abstractions of $\mathrm{H}_{20}$ and $\mathrm{H}_{22}$ have lower barriers and require lower reaction heats. The energy barriers of these two H-abstraction reactions by $\mathrm{O}_{3}$ molecules are lower than for alkanes or aldehydes (Timerghazin et al., 1999; Yang et al., 2008; Voukides et al., 2009). Moreover, $\Delta G$ for the $\mathrm{H}_{20}$ and $\mathrm{H}_{22}$ abstraction processes is less than zero, while for other processes it is larger than zero, as shown in Tables 1 and $\mathrm{S} 1$. These results indicate that $\mathrm{C}_{\alpha} \mathrm{H}$ on the $\mathrm{N}, \mathrm{N}$-diethyl group possesses high reactivity, meaning that $\mathrm{H}$-atom abstraction by $\mathrm{O}_{3}$ can occur easily under normal atmospheric conditions. With a potential barrier of $21.3 \mathrm{kcal} \mathrm{mol}^{-1}$ and a reaction heat of $2.3 \mathrm{kcal} \mathrm{mol}^{-1}, \mathrm{H}$ abstraction from the methyl group $\left(\mathrm{H}_{33}\right)$ by $\mathrm{O}_{3}$ may also take place in the atmosphere. The oxidation of the methyl group has ever been observed in the degradation of PMM in industrial water under ozone treatment (Chiron et al., 1998). In contrast, abstractions of $\mathrm{H}_{24}, \mathrm{H}_{27}, \mathrm{H}_{34}$, and $\mathrm{H}_{38}$ by $\mathrm{O}_{3}$ are energetically unfavorable.

\subsubsection{Hydroxylation and $N$-dealkylation reactions}

Generally, after $\mathrm{H}$ abstraction by $\mathrm{O}_{3}$, the $\mathrm{OOOH}$ radical will either recombine with $\mathrm{R} \cdot$ to form $\mathrm{ROOOH}$ or decompose into the OH radical and singlet oxygen (Timerghazin et al., 1999; Cerkovnik et al., 2002; Tuttle et al., 2004). In this study, addition of an $\mathrm{OH}$ radical onto the intermediate (IM1) will result in the formation of hydroxylation product $\mathrm{P} 1$, an $\alpha$-amino alcohol. Flexible 


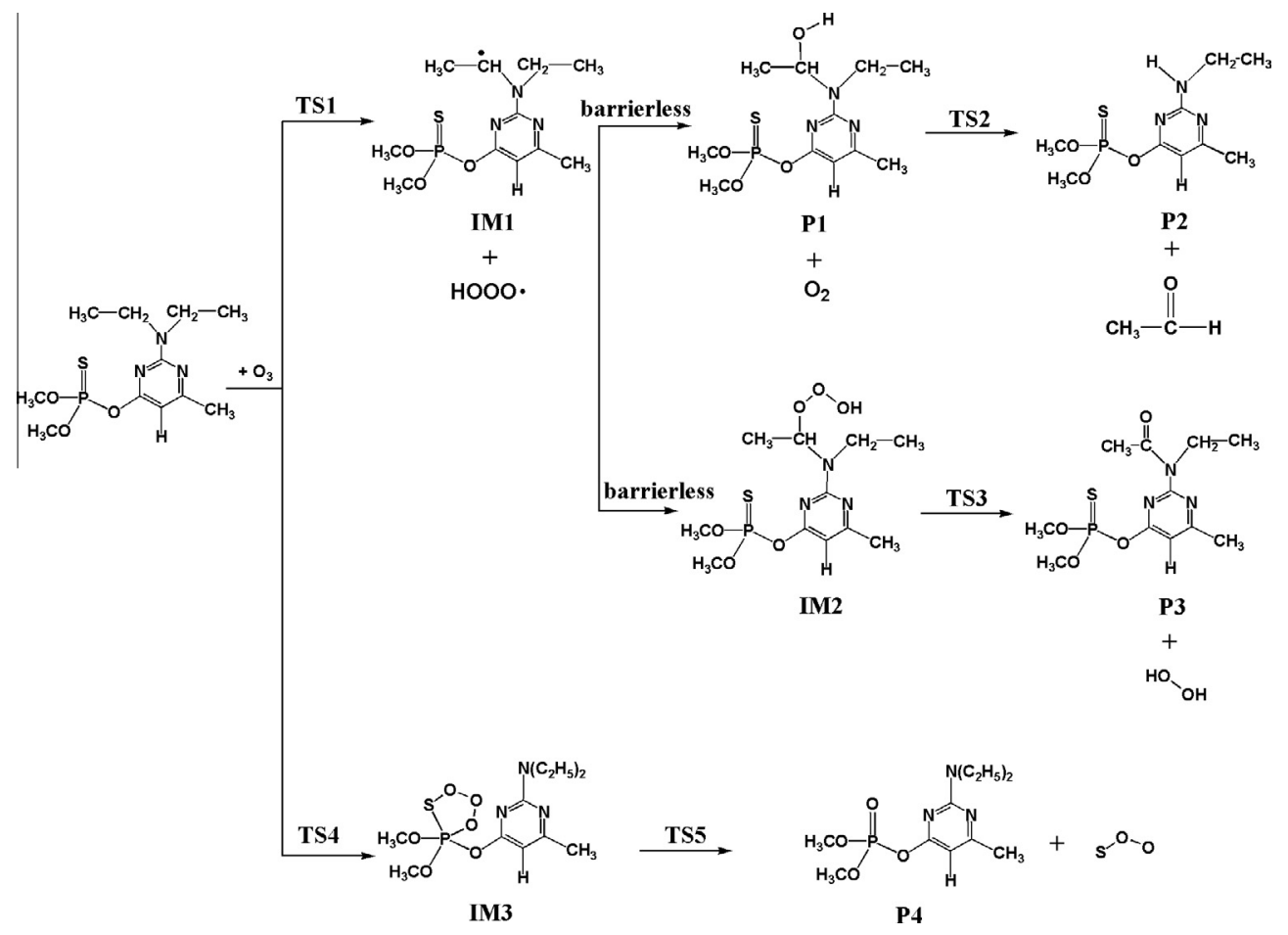

Fig. 3. Reaction pathways of PMM with $\mathrm{O}_{3}$.
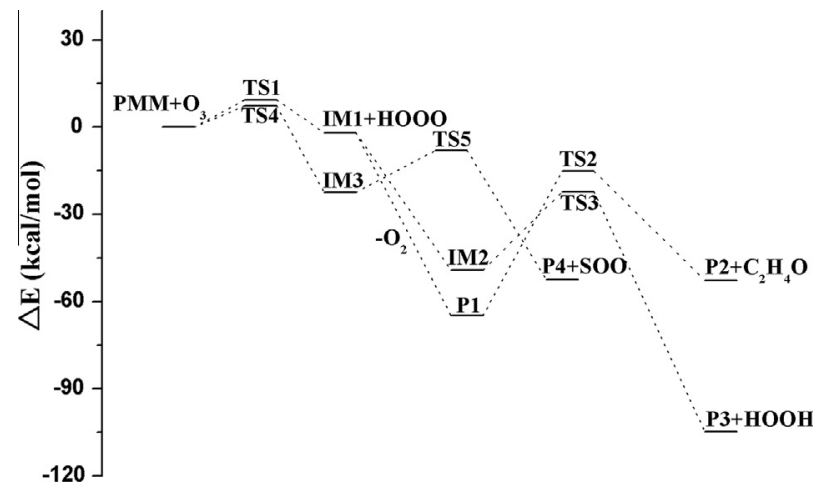

Fig. 4. Profile of the potential energy surface for the reaction of PMM with $\mathrm{O}_{3}$ obtained at the B3LYP 6-311++G(3df, 2p) level of theory.

potential energy surface scanning has been performed using the 6-31 G(d) basis set to check that this addition process is a barrierless pathway. Owing to the instability of P1, in the following step it decomposes to an $N$-dealkylation product (P2) and a molecule of acetaldehyde via transition state TS2. The mechanism of this step involves a proton transfer from the hydroxyl oxygen to the $\mathrm{N}_{6}$ atom of the $\mathrm{N}, \mathrm{N}$-diethyl group, while the $\mathrm{C}_{10} \mathrm{~N}_{6}$ bond between the alpha carbon and nitrogen atom gradually breaks. In this step, decomposing P1 requires a relatively high activation energy of $49.8 \mathrm{kcal} \mathrm{mol}^{-1}$. Since the hydroxylation reaction in the prior step is an exothermic process with a $\Delta H$ of $-62.7 \mathrm{kcal} \mathrm{mol}^{-1}$, P1 will decompose easily using this excess energy in the gas phase.

Previous studies have reported that the activation energy for decomposition of carbinolaniline is greatly reduced by the participation of a water molecule in the reaction (Wang et al., 2007; Li et al., 2009). This may imply that the $N$-dealkylation process is favorable in the presence of water. Therefore, we performed two different processes for decomposing P1: a direct reaction and a water-assisted reaction. As shown in Fig. 5(a), for the direct reaction (red line), involving transition state TS2, the proton is transferred directly from the hydroxyl oxygen to the nitrogen atom. For the water-assisted reaction (blue line), involving transition state TS2, the water molecule acts as a bridge gradually transferring a proton to the nitrogen atom while accepting the proton from the hydroxyl group. Thermodynamic data reveals that in the presence of water, the $N$-dealkylation process proceeds predominantly via the water-assisted reaction. This is mainly because the waterassisted reaction stabilizes the transition state and significantly

Table 1

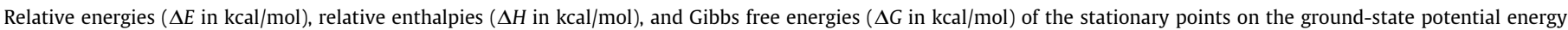

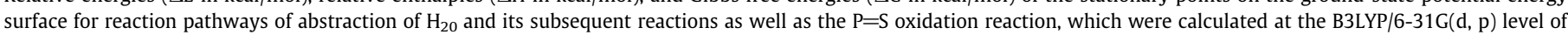
theory and relative energies $(\Delta E$ in $\mathrm{kcal} / \mathrm{mol})$ at the $\mathrm{B} 3 \mathrm{LYP} / 6-311++\mathrm{G}(3 \mathrm{df}, 2 \mathrm{p})$ level of theory.

\begin{tabular}{|c|c|c|c|c|}
\hline & \multirow{2}{*}{$\begin{array}{l}\text { 6-311++G (3df, 2p) } \\
\Delta E\end{array}$} & \multicolumn{3}{|l|}{$6-31 G(d, p)$} \\
\hline & & $\Delta E$ & $\Delta H$ & $\Delta G$ \\
\hline $\mathrm{PMM}+\mathrm{O}_{3} \rightarrow \mathrm{TS} 1 \rightarrow \mathrm{IM} 1+\mathrm{HOOO}$ & 9.4 & 8.7 & 1.5 & -0.9 \\
\hline $\mathrm{IM} 1+\mathrm{HOOO} \rightarrow \mathrm{P} 1+\mathrm{O}_{2}$ & Barrierless & Barrierless & -62.7 & -58.8 \\
\hline $\mathrm{P} 1 \rightarrow \mathrm{TS} 2 \rightarrow \mathrm{P} 2+\mathrm{CH}_{3} \mathrm{CHO}$ & 49.8 & 44.4 & 4.7 & -9.1 \\
\hline IM1 + HOOO $\rightarrow$ IM2 & Barrierless & Barrierless & -47.7 & -32.8 \\
\hline $\mathrm{IM} 2 \rightarrow \mathrm{TS} 3 \rightarrow \mathrm{P} 3+\mathrm{HOOH}$ & 27.1 & 25.1 & -49.2 & -60.3 \\
\hline $\mathrm{PMM}+\mathrm{O}_{3} \rightarrow \mathrm{TS} 4 \rightarrow \mathrm{IM} 3$ & 7.3 & 9.0 & -19.4 & -5.0 \\
\hline IM3 $\rightarrow$ TS5 $\rightarrow$ P4 + SOO & 14.4 & 13.4 & -24.4 & -38.7 \\
\hline
\end{tabular}



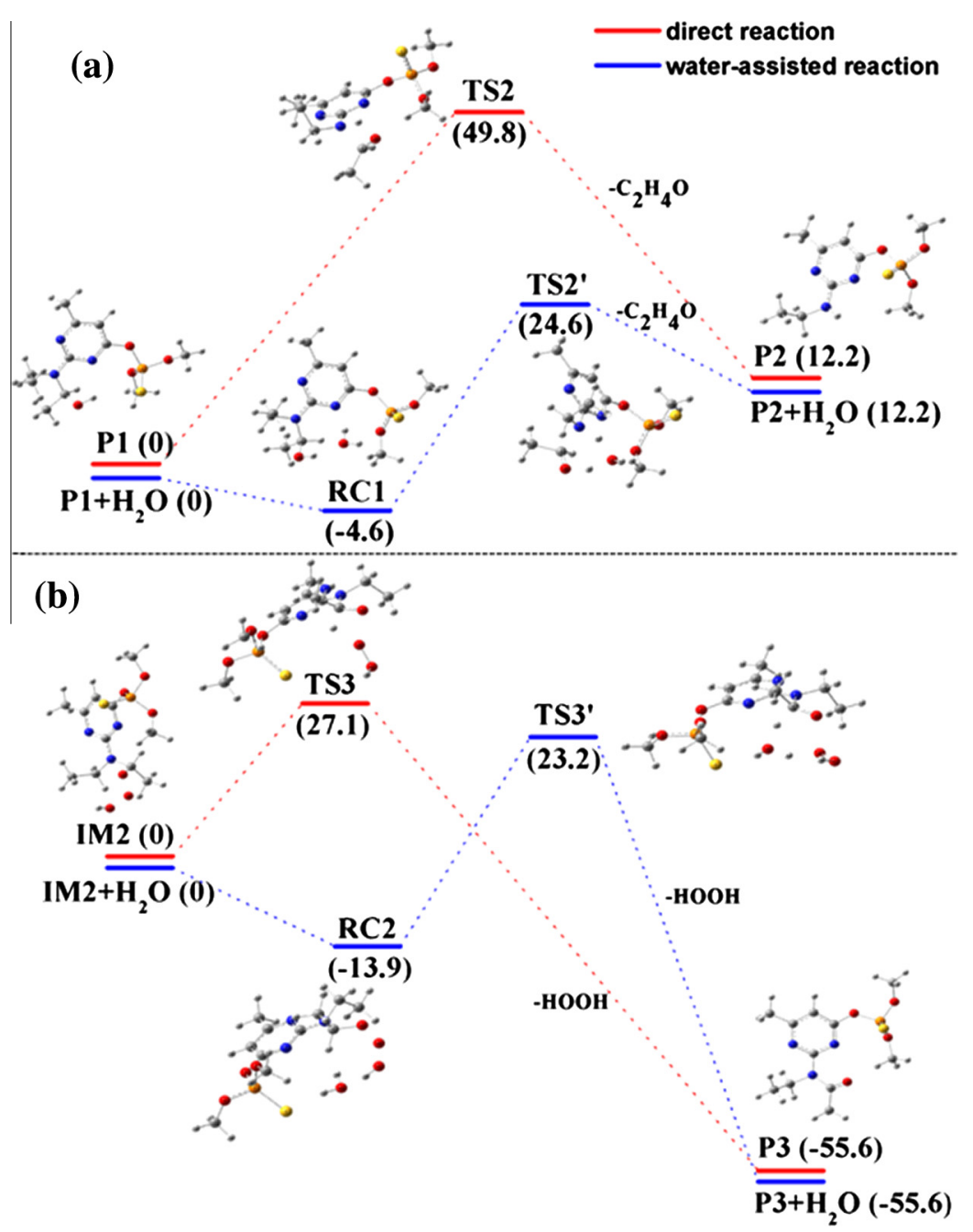

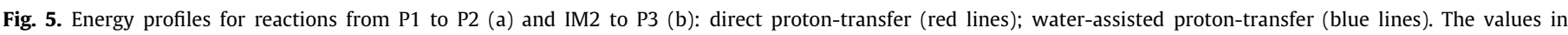

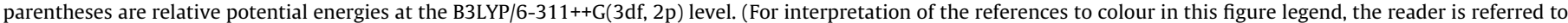
the web version of this article.)

lowers the reaction barrier. The energy of TS2' is $25.2 \mathrm{kcal} \mathrm{mol}^{-1}$ lower than that of TS2, and the reaction barrier is reduced by $20.2 \mathrm{kcal} \mathrm{mol}^{-1}$ than that of direct reaction. Moreover, the initial step of the water-assisted reaction is to form a hydrogen-bonding reaction complex (RC1), releasing $9.5 \mathrm{kcal} \mathrm{mol}^{-1}$ of heat that assists the subsequent reaction. The large barrier decrease of the water-assisted reaction can be derived from the fact that decomposition of P1 is a pericyclic proton-transfer process, as is depicted in Fig. 5(a). The transition state of the direct proton-transfer process is a rhomboid, whereas it becomes hexagonal with the addition of the water molecule. The smaller tension of a hexagon compared with a rhomboid leads to the decrease in the barrier.

Since gaseous water or adsorbed water on aerosol surfaces is ubiquitous in the ambient atmosphere, we can speculate that the water-assisted reaction should dominate ozone-induced $N$-dealkylation reactions under normal atmospheric conditions. Based on the calculated free energy $(\Delta G)$ shown in Tables 1 and $\mathrm{S} 1$, once an $\mathrm{H}$-atom is abstracted by $\mathrm{O}_{3}$, the subsequent hydroxylation and $\mathrm{N}$-dealkylation reactions on the $\mathrm{N}, \mathrm{N}$-diethyl group would tend to take place more spontaneously. Additionally, $N$-dealkylation products have been widely observed in the atmospheric degradation of pesticides that contain $N, N$-dialkyl groups (Atkinson et al., 1999). It follows that atmospheric reactions initiated by other stronger oxidants would also lead to $\mathrm{N}$-dealkylation of these substances: for example, the abstraction of $\mathrm{C}_{\alpha} \mathrm{H}$ (on the $\mathrm{N}, \mathrm{N}$-dialkyl group) by
$\mathrm{OH}$ or $\mathrm{NO}_{3}$ radicals, and direct hydroxylation by $\mathrm{OH}$ radicals. The generated $\alpha$-amino alcohol would decompose spontaneously into $\mathrm{N}$-dealkylation products and corresponding aldehydes.

\subsubsection{Carbonylation reaction}

After $\mathrm{H}$ abstraction by $\mathrm{O}_{3}$, the subsequent pathway is the recombination of the $\mathrm{OOOH}$ radical with IM1, yielding IM2, as shown in Fig. 3. This process is also a barrierless pathway, and is exothermic, releasing $47.7 \mathrm{kcal} \mathrm{mol}^{-1}$ of energy. Subsequently, the hydrogen proton gradually transfers from $\mathrm{C}_{\alpha} \mathrm{H}$ to the beta oxygen atom, while the bond between the alpha and beta oxygen atoms gradually breaks up, leading to carbonylation product P3 and $\mathrm{HOOH}$. This step proceeds through a transition state TS3 with a potential energy barrier of $27.1 \mathrm{kcal} \mathrm{mol}^{-1}$. The smaller energy barrier compared with that of the $N$-dealkylation reaction ( $49.8 \mathrm{kcal} \mathrm{mol}^{-1}$ ) may be due to the fact that the four bond angles of the quadrangle for the proton-transfer process in TS3 are more similar than those in TS2, resulting in a smaller tension in TS3. The calculated free energy $(\Delta G)$ indicates that the carbonylation reaction will be spontaneous once an $\mathrm{H}$ atom is abstracted by $\mathrm{O}_{3}$. Similar to the $\mathrm{N}$-dealkylation reaction, the carbonylation reaction is also reported as an important atmospheric degradation pathway for pesticides containing N,N-dialkyl groups (Yang et al. 2008, 2010; Atkinson et al., 1999; Meng et al., 2009). 


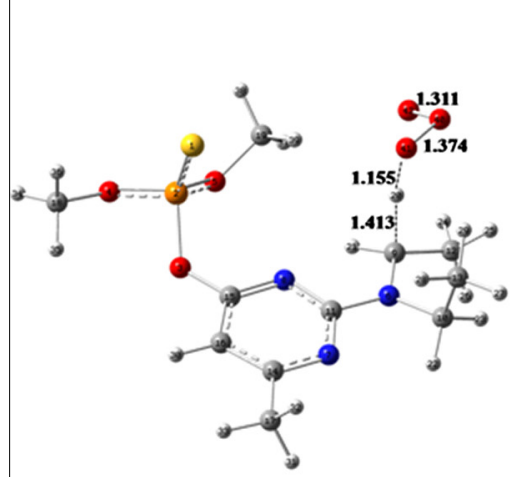

TS1

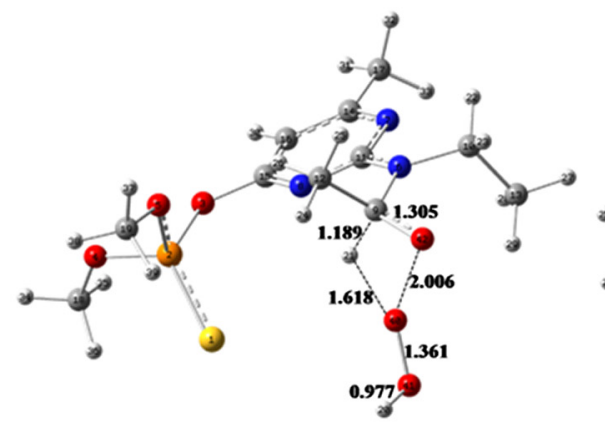

TS3

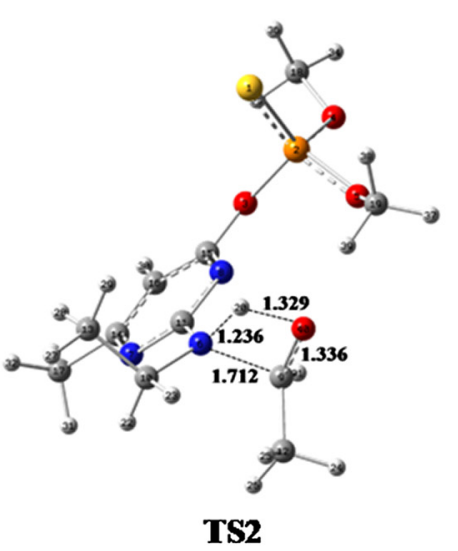

TS2

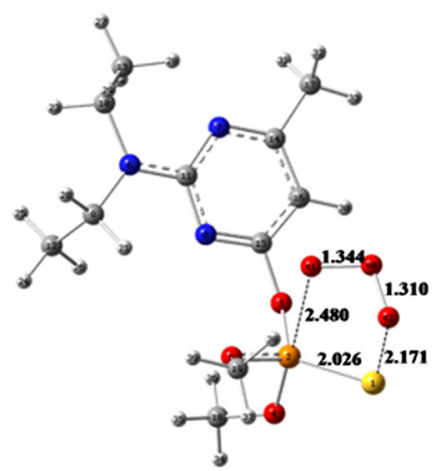

TS4
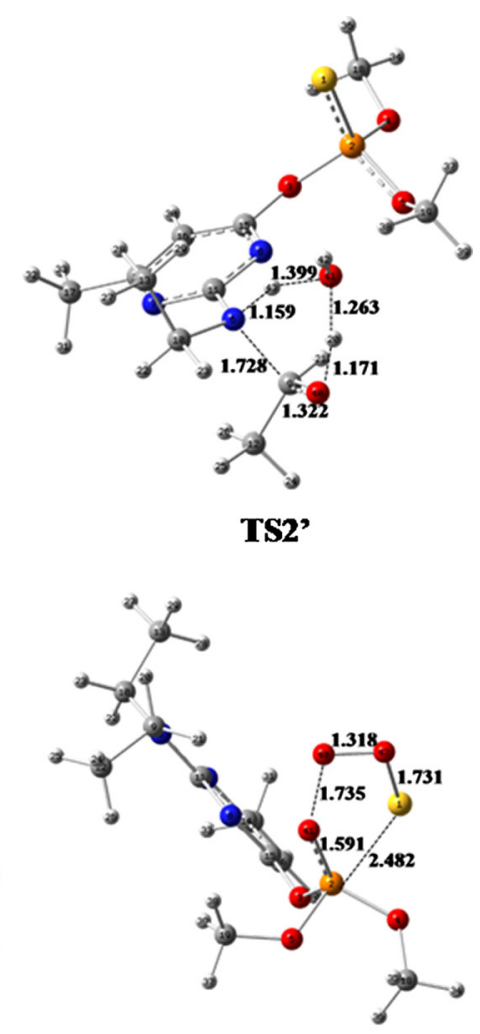

TS5

Fig. 6. Optimized geometries of transition states involved in the reaction of PMM with $\mathrm{O}_{3}$. The unit of the distances is angstrom.

Since the decomposition of the intermediate IM2 also involves a pericyclic proton-transfer process, the reaction energy barrier may again be reduced with the assistance of water. However, the impact of water on the reduction in the energy barrier for the carbonylation reaction is not as remarkable as for the $N$-dealkylation reaction. As shown in Fig. 5(b), the water-assisted reaction involves a reaction complex RC2 and a transition state TS3'. The barrierless formation of RC2 releases $17.2 \mathrm{kcal} \mathrm{mol}^{-1}$ of heat and the energy of TS3' is just $3.9 \mathrm{kcal} \mathrm{mol}^{-1}$ lower than that of TS3. We speculate that although the transition state of the proton-transfer process also changes from a quadrangle to a hexagon with the participation of water, the decrease in tension between TS3 and TS3' is smaller than between TS2 and TS2'.

\subsection{Oxidation of the $P=S$ bond}

In addition to $\mathrm{H}$ abstraction and its subsequent reactions, the oxidation of the $\mathrm{P}=\mathrm{S}$ bond is another reaction pathway for PMM and $\mathrm{O}_{3}$. As shown in Fig. 3, the reaction initiates with the addition of $\mathrm{O}_{3}$ to the $\mathrm{P}=\mathrm{S}$ bond to form a five-membered ring. This process yields an intermediate IM3 via transition state TS4. Flexible potential energy surface scanning using the $6-31 \mathrm{G}(\mathrm{d})$ basis set is performed by altering the bond lengths of PO and SO bonds of IM3 to find the transition state TS4. The obtained potential energy surface is shown in Fig. S1. In TS4, the bond lengths of PO and SO bonds are 2.480 and $2.171 \AA$, respectively, 0.703 and $0.453 \AA$ A longer than the PO and SO bonds in IM3. The potential energy barrier of this addition reaction is calculated as $7.3 \mathrm{kcal} \mathrm{mol}^{-1}$ and it releases $19.4 \mathrm{kcal} \mathrm{mol}^{-1}$ of heat. In the second step, with the increasing length of the PS bond and the decreasing length of the PO bond in IM3, the sulfur atom on the PS bond is substituted by an oxygen atom from the $\mathrm{O}_{3}$ molecule via transition state TS5, generating the final product P4 (PMM-oxon) and a molecule of SOO. This step requires a potential energy barrier of $14.4 \mathrm{kcal} \mathrm{mol}^{-1}$ and releases $24.4 \mathrm{kcal} \mathrm{mol}^{-1}$ of heat. The optimized geometries of transition states including TS1, TS2, TS2', TS3, TS4, and TS5 are shown in Fig. 6.

The transformation of the $\mathrm{P}=\mathrm{S}$ bond to the $\mathrm{P}=\mathrm{O}$ oxone form is a very common degradation pathway for organophosphorus pesticides in the atmosphere (FinlaysonPitts and Pitts, 1997). It has been reported that the oxygen analog $(\mathrm{P}=\mathrm{O})$ had a more effective toxicity than the thionphosphoryl function $(\mathrm{P}=\mathrm{S})$ of organophosphorus pesticides (Yan et al., 2008). Therefore, the potential risk of degradation product P4 to the human health may be more serious than that of PMM.

\section{Conclusions}

For the first time, the mechanisms for gas phase reactions of PMM with $\mathrm{O}_{3}$ were studied in detail by the DFT method. All stationary points involved in the reaction were optimized by the B3LYP method in conjunction with the $6-31 \mathrm{G}(\mathrm{d}, \mathrm{p})$ basis set, and more accurate energies were calculated with the $6-311++G(3 d f, 2 p)$ basis set. The results reveal that the main reaction pathways for $\mathrm{PMM}$ and $\mathrm{O}_{3}$ involve $\mathrm{H}$ abstraction from the alkyl group and its subsequent reactions, as well as the transformation of the $\mathrm{P}=\mathrm{S}$ bond into the $\mathrm{P}=\mathrm{O}$ oxone form. These reaction channels can yield four kinds of degradation product: the hydroxylation product (P1), $N$-dealkylation product (P2), carbonylation product (P3), and PMM-oxon (P4). In the $\mathrm{H}$ abstraction channels, $\mathrm{C}_{\alpha} \mathrm{H}$ on the $\mathrm{N}, \mathrm{N}$-diethyl group possesses the highest reactivity, and abstraction of this $\mathrm{H}$-atom by $\mathrm{O}_{3}$ can occur easily under ordinary atmospheric conditions. The free energy $(\Delta G)$ indicates that the subsequent reactions (hydroxylation, $N$-dealkylation, and 
carbonylation reactions) tend to take place more spontaneously once the reaction initiates. Moreover, ambient water can serve as a catalyst in the $\mathrm{N}$-dealkylation reaction process. When a water molecule assists the reaction, the energy barrier for the $\mathrm{N}$-dealkylation process is greatly reduced (by as much as $20.2 \mathrm{kcal} \mathrm{mol}^{-1}$ ). Given that atmospheric water is ubiquitous, the water-assisted reaction may dominate the $\mathrm{N}$-dealkylation process under atmospheric conditions. The proposed products based on the theoretical calculations carried out in this study match observations of the degradation of PMM under various circumstances. These theoretical studies may shed light on $\mathrm{O}_{3}$-initiated degradation mechanisms for PMM and its analogues.

\section{Acknowledgment}

This work was funded by National Natural Science Foundation of China (Grant Nos. 21207143 and 21277155).

\section{Appendix A. Supplementary material}

Supplementary data associated with this article can be found, in the online version, at http://dx.doi.org/10.1016/j.chemosphere. 2014.12.039.

\section{References}

Atkinson, R., Guicherit, R., Hites, R.A., Palm, W.U., Seiber, J.N., de Voogt, P., 1999. Transformations of pesticides in the atmosphere: a state of the art. Water Air Soil Pollut. 115, 219-243.

Barakat, A.A., Samira, A.A., Badawy, H.M.A., Sammour, E.A., Soliman, M.M.M., 1994 Persistence of profenofos and pirimiphos-methyl in green cowpea pods and on films exposed to ultra-violet and sun rays. Bull. Ent. Soc. Egypt Econ. Ser. 21, $103-112$.

Cerkovnik, J., Erzen, E. Koller, J. Plesnicar, B, 2002. Evidence for HOOO radicals in the formation of alkyl hydrotrioxides $(\mathrm{ROOOH})$ and hydrogen trioxide $(\mathrm{HOOOH})$ in the ozonation of $\mathrm{C}-\mathrm{H}$ bonds in hydrocarbons. J. Am. Chem. Soc. 124, 404409.

Chiron, S., Rodriguez, A., Fernandez-Alba, A., 1998. Application of gas and liquid chromatography mass spectrometry to the evaluation of pirimiphos methyl degradation products in industrial water under ozone treatment. J. Chromatogr. A 823, 97-107.

Crane, M., Attwood, C., Sheahan, D., Morris, S., 1999. Toxicity and bioavailability of the organophosphorus insecticide pirimiphos methyl to the freshwater amphipod Gammarus pulex L-in laboratory and mesocosm systems. Environ. Toxicol. Chem. 18, 1456-1461.

FinlaysonPitts, B.J., Pitts, J.N., 1997. Tropospheric air pollution: ozone, airborne toxics, polycyclic aromatic hydrocarbons, and particles. Science 276, 1045 1052.

Fleurat-Lessard, F., Chaurand, M., Marchegay, G., Abecassis, J., 2007. Effects of processing on the distribution of pirimiphos-methyl residues in milling fractions of durum wheat. J. Stored Prod. Res. 43, 384-395.

Frisch, M.J. et al., 2009. Gaussian 09. Revision A.02. Gaussian, Inc., Wallingford, CT.

Gescher, A., 1990. A toxicological detective-story. Chem. Br. 26, 435-438.

Hanna, P.J., Dyer, K.F., 1975. Mutagenicity of organophosphorus compounds in bacteria and drosophila. Mutat. Res. 28, 405-420.

Herrmann, J.M., Guillard, C., Arguello, M., Aguera, A., Tejedor, A., Piedra, L., Fernandez-Alba, A., 1999. Photocatalytic degradation of pesticide pirimiphosmethyl - determination of the reaction pathway and identification of intermediate products by various analytical methods. Catal. Today 54, 353-367.

Hladka, A., Valkyova, I., Chabrecek, P., 1991. Evaluation of professional exposure to pirimiphos methyl actellic. Sci. Total Environ. 101, 177.
Li, D., Wang, Y., Yang, C., Han, K., 2009. Theoretical study of N-dealkylation of Ncyclopropyl-N-methylaniline catalyzed by cytochrome P450: insight into the origin of the regioselectivity. Dalton Trans., 291-297.

Lock, E.A., Johnson, M.K., 1990. Delayed neuropathy and acute toxicity studies with pirimiphos-methyl in the hen. J. Appl. Toxicol. 10, 17-21.

Meng, J., Yang, B., Zhang, Y., Shu, X., Shu, J., 2009. Ozonation of trifluralin particles: an experimental investigation with a vacuum ultraviolet photoionization aerosol time-of-flight mass spectrometer. J. Hazard. Mater. 172, 390-394.

Meylan, W.M., Howard, P.H., 1993. Computer estimation of the atmospheric gasphase reaction-rate of organic-compounds with hydroxyl radicals and ozone. Chemosphere 26, 2293-2299.

Moriya, M., Ohta, T., Watanabe, K., Miyazawa, T., Kato, K., Shirasu, Y., 1983. Further mutagenicity studies on pesticides in bacterial reversion assay systems. Mutat. Res. 116, 185-216.

Ngufor, C., Tchicaya, E., Koudou, B., N'Fale, S., Dabire, R., Johnson, P., Ranson, H., Rowland, M., 2014. Combining organophosphate treated wall linings and longlasting insecticidal nets for improved control of pyrethroid resistant anopheles gambiae. Plos One 9.

Ohashi, N., Tsuchiya, Y. Sasano, H., Hamada, A., 1994. Ozonation products of organophosphorous pesticides in water. Jpn. J. Toxicol. Environ. Health 40, 185 192.

Oxborough, R.M., Kitau, J., Jones, R., Feston, E., Matowo, J., Mosha, F.W., Rowland, M.W., 2014. Long-lasting control of Anopheles arabiensis by a single spray application of micro-encapsulated pirimiphos-methyl (Actellic (R) 300 CS). Malaria J.13.

Rajini, P.S., Muralidhara Krishnakumari, M.K., Majumder, S.K., 1986. Mutagenic properties of pirimiphos-methyl in male-mice. Bull. Environ. Contam. Toxicol. 36, 680-684.

Robbins, P.J., Cherniack, M.G., 1986. Review of the biodistribution and toxicity of the insect repellent n,n-diethyl-m-toluamide (DEET). J. Toxicol. Environ. Health 18, 503-525.

Ross, D., Farmer, P.B., Gescher, A., Hickman, J.A., Threadgill, M.D., 1983. The formation and metabolism of n-hydroxymethyl compounds.3. The metabolic conversion of n-methyl and n,n-dimethylbenzamides to n-hydroxymethyl compounds. Biochem. Pharmacol. 32, 1773-1781.

Seiler, J.P., 1973. Survey on mutagenicity of various pesticides. Experientia 29, 622623.

Singh, S., Kumar, V., Thakur, S., Banerjee, B.D., Chandna, S., Rautela, R.S., Grover, S.S. Rawat, D.S., Pasha, S.T., Jain, S.K., Ichhpujani, R.L., Rai, A., 2011. DNA damage and cholinesterase activity in occupational workers exposed to pesticides. Environ. Toxicol. Pharmacol. 31, 278-285.

Tangena, J.-A.A., Adiamoh, M., D’Alessandro, U., Jarju, L., Jawara, M., Jeffries, D. Malik, N., Nwakanma, D., Kaur, H., Takken, W., Lindsay, S.W., Pinder, M., 2013. Alternative treatments for indoor residual spraying for malaria control in a village with pyrethroid- and DDT-resistant vectors in The Gambia. Plos One 8.

Timerghazin, Q.K., Khursan, S.L., Shereshovets, V.V., 1999. Theoretical study of the reaction between ozone and $\mathrm{C}-\mathrm{H}$ bond: gas-phase reactions of hydrocarbons with ozone. J. Mol. Struct. Theochem. 489, 87-93.

Tuttle, T., Cerkovnik, J., Plesnicar, B., Cremer, D., 2004. Hemiortho esters and hydrotrioxides as the primary products in the low-temperature ozonation of cyclic acetals: an experimental and theoretical investigation. J. Am. Chem. Soc. 126, 16093-16104.

Vingarzan, R., 2004. A review of surface ozone background levels and trends. Atmos. Environ. 38, 3431-3442.

Voukides, A.C., Konrad, K.M., Johnson, R.P., 2009. Competing mechanistic channels in the oxidation of aldehydes by ozone. J. Org. Chem. 74, 2108-2113.

Wang, Y., Kumar, D., Yang, C., Han, K., Shaik, S., 2007. Theoretical study of Ndemethylation of substituted N,N-dimethylanilines by cytochrome P450: the mechanistic significance of kinetic isotope effect profiles. J. Phys. Chem. B 111, $7700-7710$.

WHO Specifications and Evaluations for Public Health Pesticides, PirimiphosMethyl, 19.

Yan, D., Jiang, X., Xu, S., Wang, L., Bian, Y., Yu, G., 2008. Quantitative structuretoxicity relationship study of lethal concentration to tadpole (Bufo vulgaris formosus) for organophosphorous pesticides. Chemosphere 71, 1809-1815.

Yang, J., Li, Q.S., Zhang, S., 2008. Direct dynamics study on the reaction of acetaldehyde with ozone. J. Comput. Chem. 29, 247-255.

Yang, B., Zhang, Y., Meng, J.W., Gan, J., Shu, J.N., 2010. Heterogeneous reactivity of suspended pirimiphos-methyl particles with ozone. Environ. Sci. Technol. 44, 3311-3316. 